Article

\title{
Optimizing the Management Strategies of a Multi-Purpose Multi-Reservoir System in Vietnam
}

\author{
Frederick N.-F. Chou ${ }^{1}$, Nguyen Thi Thuy Linh ${ }^{1,2, *}$ and Chia-Wen $\mathrm{Wu}^{1}$ \\ 1 Department of Hydraulic and Ocean Engineering, National Cheng Kung University, No. 1, University Rd., \\ Tainan 701, Taiwan; hyd4691@mail.ncku.edu.tw (F.N.-F.C.); chiawenwu1977@gmail.com (C.-W.W.) \\ 2 Faculty of Water Resource Engineering, Thuyloi University, Hanoi 100000, Vietnam \\ * Correspondence: linhntt@tlu.edu.vn
}

Received: 22 February 2020; Accepted: 23 March 2020; Published: 26 March 2020

\begin{abstract}
Resource shortages are having an increasingly severe impact as global trends like rapid population growth, urbanization, economic development, and climate change unfold. Moreover, rising living standards across many regions are also affecting water and energy resources. This entails an urgent requirement to improve water resources management. An important improvement is to transfer water between the different uses of the reservoir system. A compromise between the needs of hydropower generation and the water supply can be negotiated for the reservoir system to reduce the severity of water shortages. The Be River basin in Vietnam was selected as a case study to investigate. The combination of the generalized water allocation simulation model (GWASIM) and the bounded optimization by quadratic approximation (BOBYQA) algorithm was applied to optimize hydropower generation in various water shortage scenarios. The results present optimized hydropower generation policies for cascade reservoirs that would significantly improve the present operating policy in terms of both the water supply and hydropower generation. Moreover, multiple scenarios will provide flexibility to the reservoir operator by giving the relationship between water and energy. Given water supply conditions, the operator will be able to choose among several optimal solutions to ensure greater water resource efficiency in the Be River basin.
\end{abstract}

Keywords: cascade reservoirs; hydropower; management; shortage index; water supply

\section{Introduction}

Historical records indicate that severe drought has occurred in almost all parts of Vietnam [1,2]. Severe droughts have hit the Central Highlands, the South-Central coast of Vietnam, and the Dong Nai River basin and resulted in depleted reservoirs, crop failures, reduced groundwater, and interruptions to the water supply. These impacts demonstrate the potential vulnerability of other regions to future droughts [3-5]. Therefore, mitigation of drought damage is one of the most concerning problems for water resources management in the Dong Nai River basin. Within the Dong Nai River basin is a sub-basin called the Be River basin. The Be River basin has a cascade reservoir system comprised of three upstream reservoirs and one downstream reservoir, all located in series. Each of the three upstream reservoirs' purpose is both hydropower generation and water supply, while the remaining downstream reservoir has the sole purpose of water supply. In addition, the system helps maintain environmental flow and trans-basin water transfer. Although hydropower generation has been viewed as the primary purpose of the three upstream reservoirs since the beginning of their operation, the cascade reservoirs system in the Be River basin is increasingly expected to reduce the severity of water shortages. The management approach to recover from water shortages is to transfer water between the different uses of the reservoir system until an acceptable level of water supply in the river is reached. In this study, water resources were reallocated from hydropower generation to water 
supply. To increase the reliability of water supply, different water resource allocations were examined to negotiate a compromise between hydropower generation and water supply. Numerous studies exist and various systems analysis models have been applied to solve multi-purpose optimization problems [6-12]. In general, these models can be classified as simulation models, optimization models, and the combination of simulation and optimization models [13-17]. To precisely describe complex multi-purpose reservoir systems and performance in great detail, simulation models are preferred $[18,19]$. Simulation models are able to explore the behavior and evaluate the performance of reservoir operations but cannot optimize them. Linear programming, non-linear programming, and dynamic programming are traditional optimization approaches that are used to optimize reservoir operations. But these optimization approaches have limitations when dealing with complex reservoir systems [20]. Therefore, a combined simulation-optimization model is preferred to optimize a complex multi-purpose multi-reservoir system [20,21]. In this study, a simulation-optimization model was employed to derive optimal hydropower generation policies for the multi-purpose multi-reservoir system in the Be River basin.

When a complex reservoir system has multiple decision alternatives, the decision-makers will be overwhelmed by the difficulty of tracking system performance across multiple objectives spatially and temporally. System operators require improved performance tracking to aid in decision making. A possible approach is to use indices to evaluate system performance, and then use an index analysis to rank decision alternatives. Applying water shortage indices to evaluate the decision alternatives is especially important during periods of drought, peak demand, and extreme weather. Many shortage indices have been used by researchers to represent system performance [22-25]. For instance, the deficit percent day (DPD) index which was developed by the Japan Water Resources Development Public Corp has been used frequently in the United States and Japan [22,26,27]. The shortage index (SI) was adopted to represent water shortages in many studies [22,28-32] and used as design criteria for developing new water resources projects. The reliability, resiliency, and vulnerability criteria were also used to assess the impact of water shortage for the water resource system [23,33-40]. In this study, the shortage indices are adopted to describe the characteristics of shortage situations for agriculture, domestic and industrial water supply more precisely. The shortage rate (SR), shortage index (SI) and deficit percent day index (DPD) were applied in this study to capture water resource situations. The SR and SI, serving as the first-order and second-order index respectively, describe the average deficit ratio and average squared deficit ratio of water shortage events. Both indices are frequently used to expose the total volume of the water deficit and strengthen the yearly deficit rate, but fail to explore the duration and intensity of a severe shortage event. Even if the SR and SI are small, the possible consequences of the shortage index require more attention at probable extreme events that can occur in the simulation period. To capture this missed granularity by detailing variations of each deficit, the extreme-index DPD, can be used to describe the performance of the water supply of a water resources system.

This study looked at the multi-purpose multi-reservoir of the Be River basin as a case study. A simulation-optimization model was employed to maximize hydropower generation within the constraints of water shortage scenarios. The water shortage indices were adopted to more precisely describe the characteristics of shortage events. The results show a trade-off curve between water supply and energy that will provide flexibility to the reservoir operator when managing water shortages. This paper is organized as follows: Section 2 gives an introduction to the cascade reservoirs system in the Be River basin and the data set; Section 3 describes water shortage indices and the research methodology, which includes the adopted simulation-optimization model; Section 4 discusses the results, where optimized policies for different water shortage scenarios are derived, evaluated and compared to the policy currently in use; and Section 5 presents the conclusion and recommendations. 


\section{Study Area and Data Set}

The Be River basin is one of the sub-basins of the Dong Nai River basin in South Vietnam. It lies between latitudes $11^{\circ} 10^{\prime}$ to $12^{\circ} 16^{\prime} \mathrm{N}$ and longitudes $106^{\circ} 36^{\prime}$ to $107^{\circ} 30^{\prime} \mathrm{E}$. The altitude varies from El.1000 $\mathrm{m}$ in the highland area to El.100 $\mathrm{m}$ in the plains area in the direction from northeast to southwest. The Be River basin spans across 3 provinces: Binh Phuoc, Dak Nong, and Dong Nai, and has a catchment area of $7650 \mathrm{~km}^{2}$. A small portion of the Be River basin-about $200 \mathrm{~km}^{2}$-is in Cambodia. The main stream in the basin is the Be River which has a length of $350 \mathrm{~km}$. The average density of the river network is about $0.56 \mathrm{~km} / \mathrm{km}^{2}$. Figure 1 shows a map of the Be River basin with four cascade reservoirs, Thac Mo (in operation since 1994), Can Don (in operation since 2003), Srock Phu Mieng (SRPM; in operation since 2006) and Phuoc Hoa (in operation since 2014) in series from upstream to downstream. The main purpose of the cascade reservoirs in the Be River basin is to generate electricity and supply water. The Thac Mo, Can Don and SRPM reservoirs produce a large amount of electric power used for social and economic activities downstream. Phuoc Hoa, the fourth reservoir in the system, serves three critical functions; trans-basin water transfer, agricultural water supply, and environmental protection. Specifications of the reservoirs and hydropower plants information are listed in Table 1. The water demand sites in this basin can be categorized into six sub-basins, which are Upstream, Thac Mo, Can Don, SRPM, Phuoc Hoa, and Downstream. A diagram of the system is presented in Figure 2.

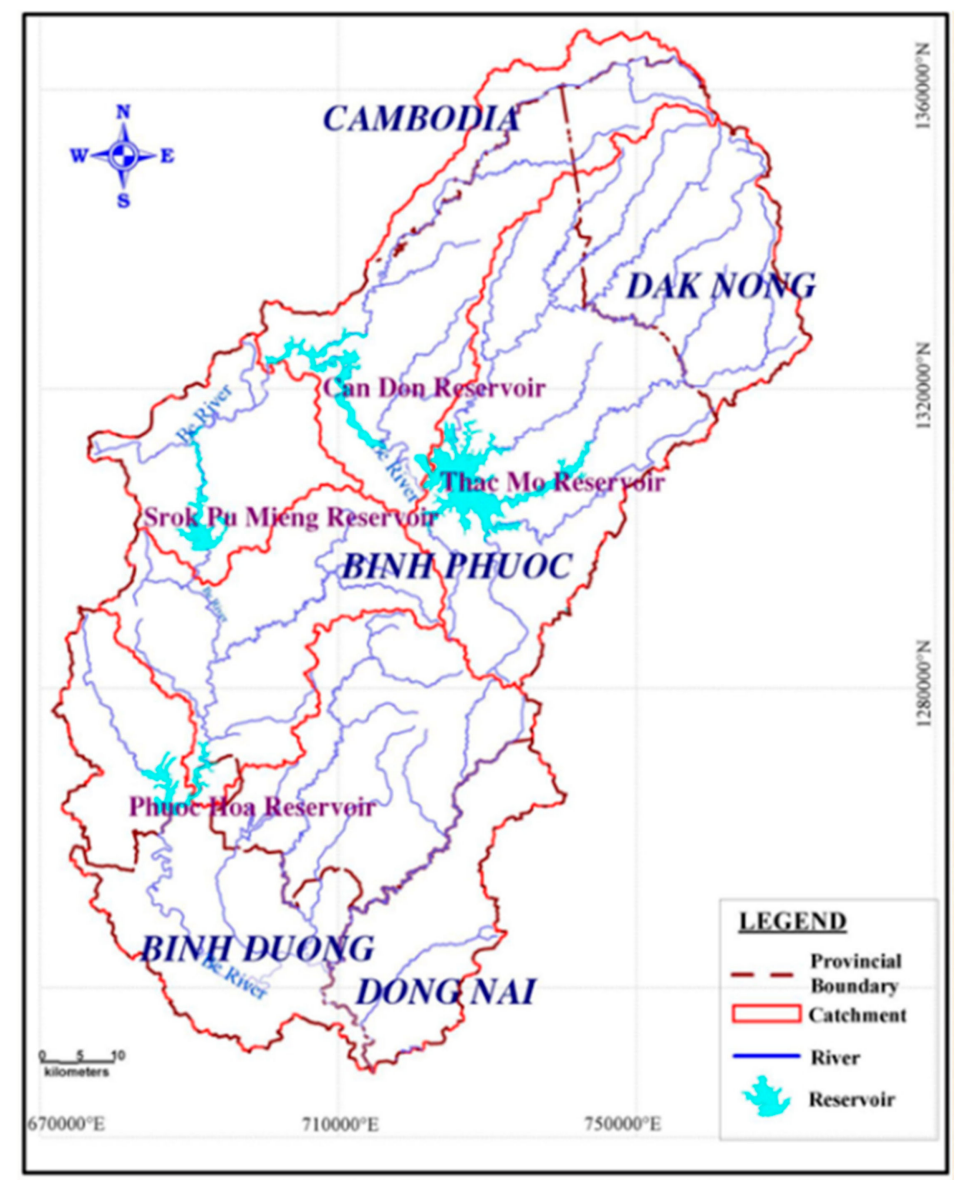

Figure 1. Location map of the Be River basin in Vietnam. 


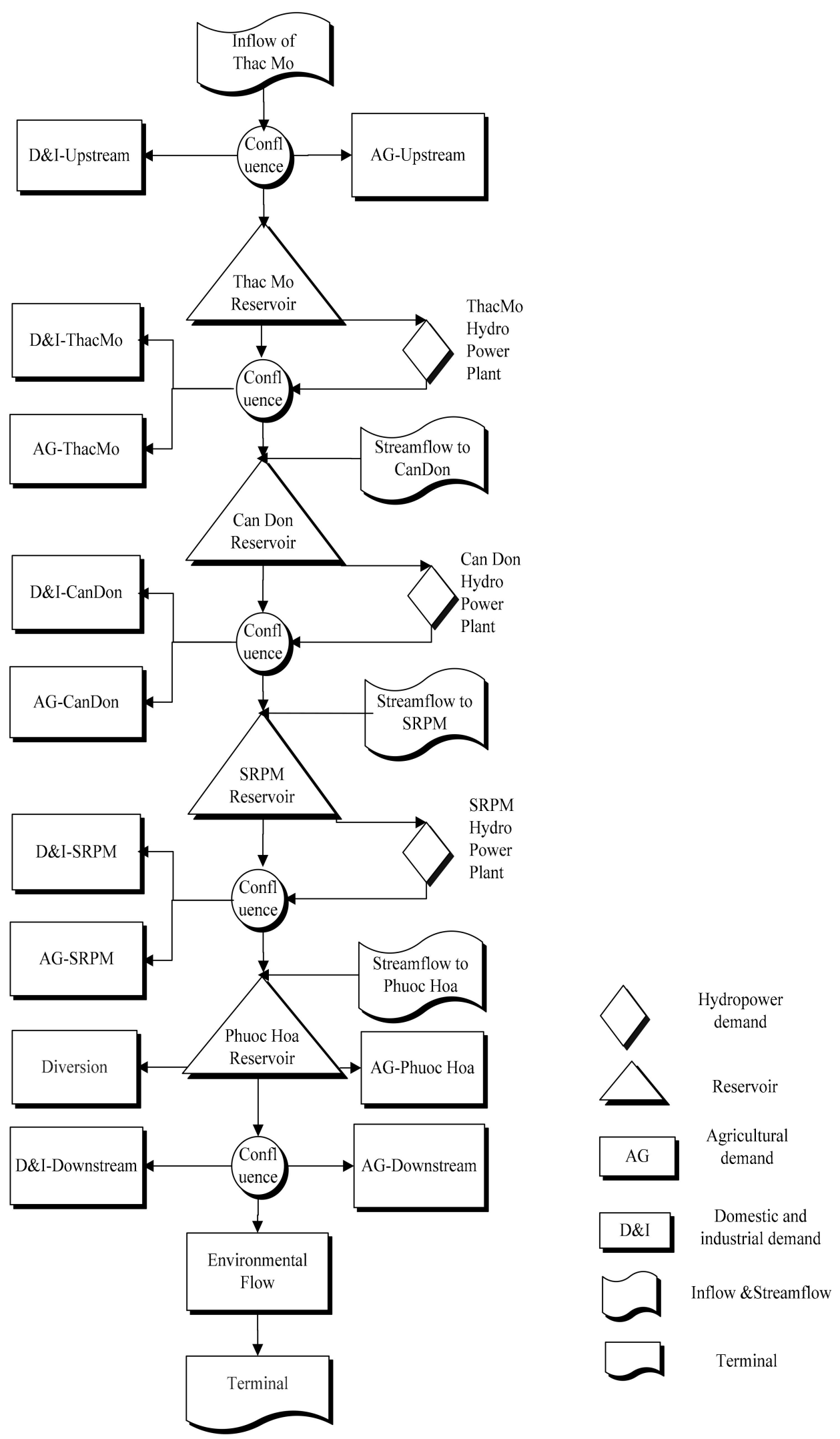

Figure 2. A node-arc representation of the Be River water resources system. 
Table 1. Operation features of cascade reservoirs.

\begin{tabular}{ccccccc}
\hline \multirow{2}{*}{ Name of Reservoir } & \multicolumn{3}{c}{ Water Level (El.m) } & \multicolumn{3}{c}{ Corresponded Storage $\left.\mathbf{( 1 0}^{\mathbf{6}} \mathbf{~}^{\mathbf{3}}\right)$} \\
\cline { 2 - 7 } & Flood Control & Active & Dead & Flood Control & Active & Dead \\
\hline Thac Mo & 220.8 & 218.0 & 198.0 & 1668.1 & 1360.0 & 110.0 \\
Can Don & 112.3 & 110.0 & 104.0 & 229.3 & 165.5 & 85.6 \\
SPM & 73.6 & 72.0 & 70.0 & 34.6 & 28.4 & 20.6 \\
Phuoc Hoa & 45.3 & 42.9 & 42.5 & 31.1 & 13.7 & 11.2 \\
\hline
\end{tabular}

Water demand values of each demand site were provided by the Southern Institute of Water Resources Planning for the year 2015. Annual rainfall varies between $1800 \mathrm{~mm}$ and $2800 \mathrm{~mm}$ and averages $2400 \mathrm{~mm}$ in the Be River basin. The rainy season begins from June to November and accounts for $85 \%$ to $90 \%$ of annual precipitation The period with the highest amount of rainfall occurs from July to September, which includes $50 \%$ to $60 \%$ of the annual rainfall. The dry season lasts from late December to May of the following year. Figure 3 shows the Box-Whisker plots of the monthly average discharges of the system from 1978 to 2010. Historical daily flows of 33-years period are used for simulation analysis in this study. A series of drought events $(1998,2001,2002,2003,2004)$ occurred in the Be River basin from 1998 to 2011. SIWRP pointed out that the 2002 event was a typical severe drought that lasted five months from September to April over this region. The total precipitation amount in the dry season accounts for approximately $1 \%-5 \%$ of the annual precipitation. Under current operations, there is a conflict between water users in the Be River basin. The reservoir operators may desire to meet sufficient water supply and maximize hydropower generation. However, increased demand for water supply reduces the amount of water available for hydropower generation. There is an urgent need for improvement of the effectiveness and efficiency of the reservoir operations. This comprehensive study helps present operating policies that are more resilient and adaptive to increasing water demand and extreme weather.

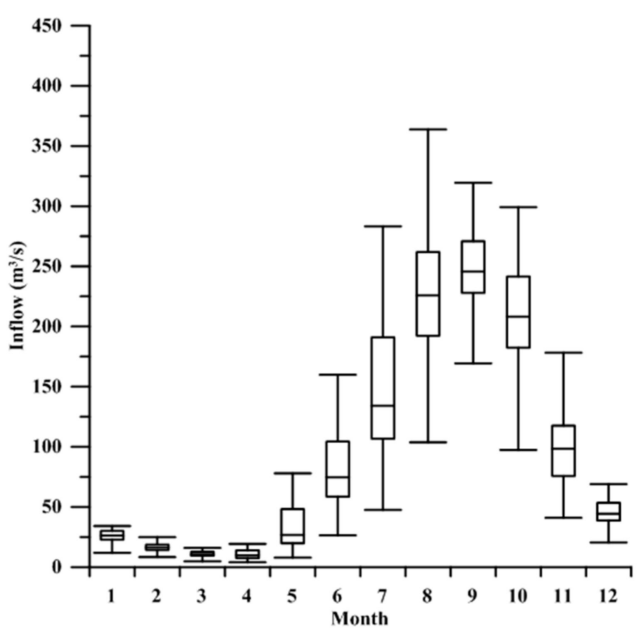

(a)

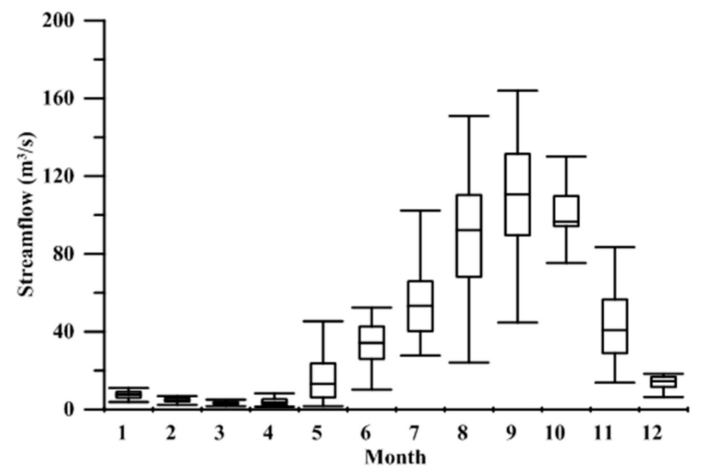

(b)

Figure 3. Cont. 


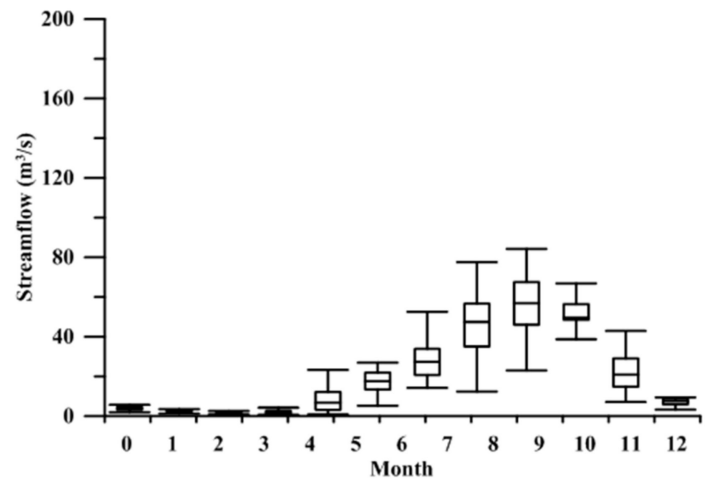

(c)

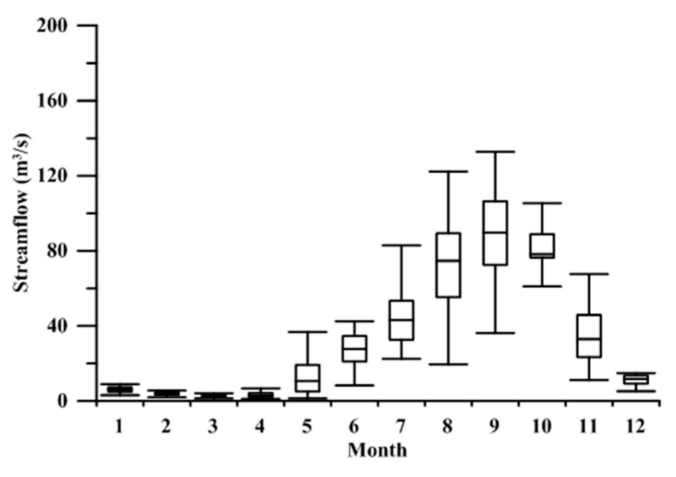

(d)

Figure 3. The Box-Whisker plots of the monthly average discharges of the system. (a) Thac Mo reservoir, (b) Can Don reservoir, (c) Srock Phu Mieng (SRPM) reservoir, (d) Phuoc Hoa reservoir.

\section{Methodology}

\subsection{Performance Indices}

\subsubsection{Shortage Rate (SR)}

In this study, SR indicates the annual water shortage rate, based on the water deficit and the designed water supply. The advantage of the SR is that it concisely captures general shortage characteristics across a time range. However, the SR does not capture the severity and the frequency of water shortages. The SR is considered as the first-order index that is used as a simple and frequent measure of system performance. Generally, the SR for a particular period is expressed as:

$$
\mathrm{SR}=\frac{\text { Deficit in a period }}{\text { Designed water supply }} \times 100 \%
$$

\subsubsection{Shortage Index (SI)}

This index is proportional to the sum of the square of the deficit rate in a set of years. This index is expressed as the equation below.

$$
\mathrm{SI}=\frac{100}{\mathrm{~N}} \sum_{\mathrm{t}=1}^{\mathrm{T}}\left(\frac{\text { Annual water deficit }}{\text { Designed annual water supply }}\right)^{2}
$$

where, $\mathrm{SI}$ is water shortage index, $\mathrm{T}$ is the number of deficit years and $\mathrm{N}$ is the number of sample years where the system was in operation.

The SI is to enlarge by the square of the shortage rate and then sum up for all indicated values of every deficit year to represent the severity of the water shortage. Therefore, the SI is used as the second-order index in this study. The advantage of this criteria is that it can describe long term water shortages across multiple years. This second-order index exposes the magnitude of water shortages and the frequency of these shortages. However, the shortcoming of this index is that the granularity; shortages and durations in a certain year are lost.

\subsubsection{Deficit Percent Day Index (DPD)}

The deficit percent day (DPD) is the product of the daily water shortage rate and the number of consecutive water shortage days. By using this criterion each water shortage event can be explored in terms of water shortage intensity and water shortage duration. DPD is one of the criteria that form the 
basis of defining water shortage tolerances, but a shortcoming is that it does not reflect the frequency of water shortages.

$$
\left.D P D=\sum \text { [Daily shortage rate }(\%) \times \text { Number of days in a continuous deficit }\right]
$$

The SR serves as the first-order index and exposes the total water volume of the water supply deficit. The SI serves as the second-order index and has the advantage of measuring the yearly deficit rate, but fails to explore the duration and intensity. The SR and SI describe the average level and average squared deviation of a water shortage event, evenly distributed in a simulation period. Even when the SR and SI are small, the possible consequences of shortage index require attention because there may have extreme events during that period. It should be noted here that severe events are of vital interest to decision-makers and water resources planners due to the potential risks. The DPD, the extreme-index, is able to capture this missed granularity by detailing variations of each deficit.

\subsection{The Framework of the Simulation-Optimization Model}

In general, systems analysis models can be classified into simulation models, optimization models, and combined simulation-optimization models. All of them can be applied to obtaining the optimal management policies for multi-purpose multi-reservoir systems. For a complex system, the simulation model is preferred to precisely describe the system and performance in great detail. However, that still leave challenges in predicting and seeking optimal operating policy solutions. An optimization model with the advantage of searching an optimal solution over a set of feasible solutions can be used to overcome this limitation. Therefore, the combination of simulation and optimization models is a preferred model to optimize a complex multi-purpose multi-reservoir system. A simulation-optimization model was employed to derive optimal hydropower generation policies for the multi-purpose multi-reservoir system in the Be River basin. The simulation analysis was carried out with each set of pre-specified decisions and evaluated the system performance. The initial decision variables were generated randomly at the beginning. The performance outputs obtained by the simulation model were assigned as the objective function. If the constraints did not satisfy, the decision variables could be replaced. The decision variables would then be updated with the proper optimization algorithm then the simulation model was executed again to provide new performance information. This procedure continued iteratively until all the termination criterion were satisfied. The framework of this simulation-optimization approach is illustrated in Figure 4. The hydropower generation policies were set up in the generalized water allocation simulation model (GWASIM) [41,42] to guide the water releases of the reservoir system based on the current hydrological conditions, i.e., reservoir water level, inflows, and demands. The bounded optimization by quadratic approximation (BOBYQA) algorithm was adopted for optimizing the daily generating hours of three cascade reservoir hydropower plants. 


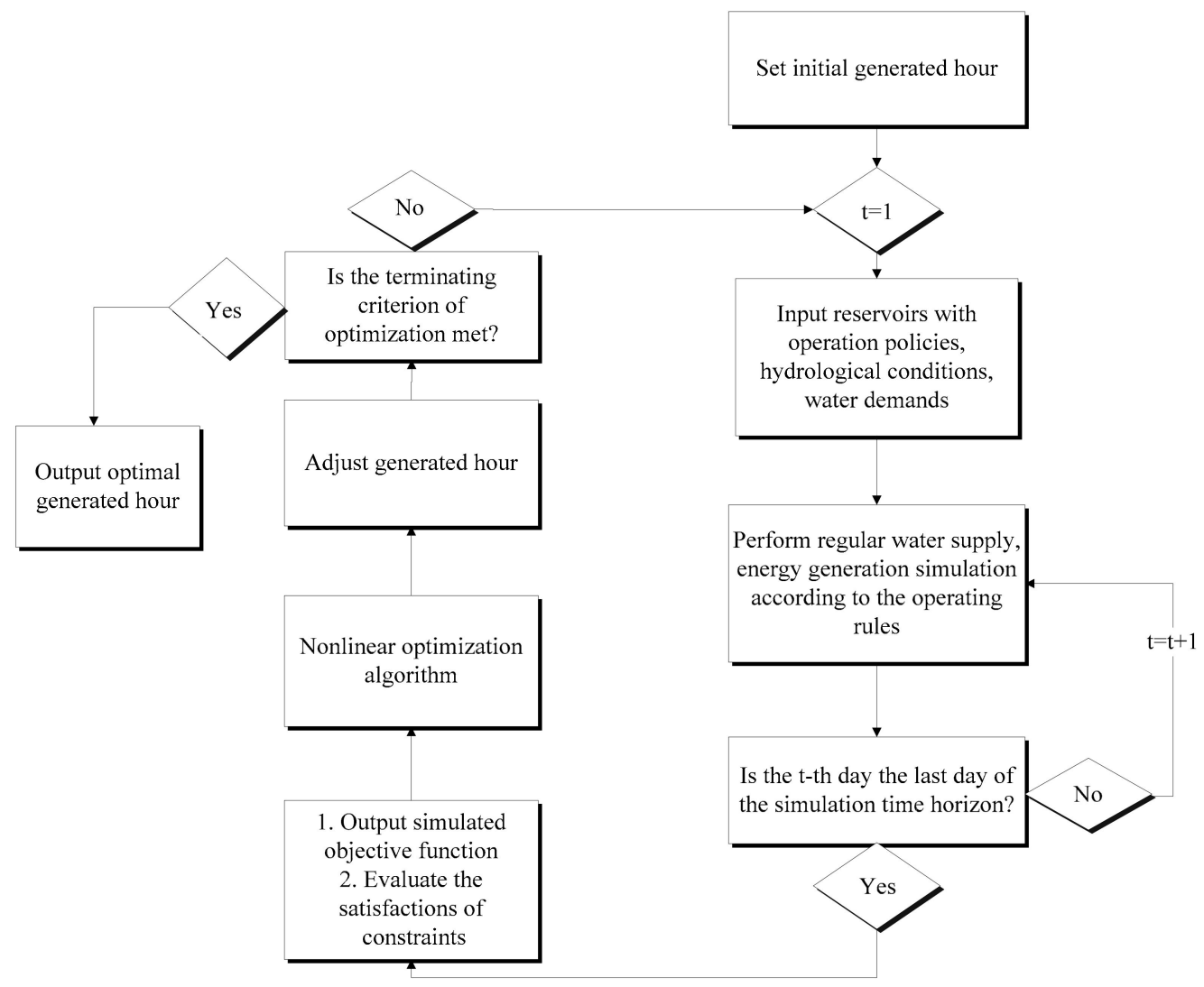

Figure 4. The framework of simulation-optimization approach.

\subsubsection{Simulation Model}

(1) Minimum cost network flow programming

Minimum cost network flow programming (NFP) is a highly efficient algorithm for minimizing the total cost of all flows in a large network. The storage and water transfers of the system were described using an artificial capacitated closed network and solved as a linear programming problem. The net inflows and outflows through the arcs were equal, and the flows were continuous. The flow through the directed arc was constrained by an upper bound and lower bound and denoted by unit shipping cost. The NFP problem with m nodes can be stated as the mathematical formulation below:

$$
\text { Minimize } \sum_{\mathrm{i}=1}^{\mathrm{m}} \sum_{\mathrm{j}=1}^{\mathrm{m}} \mathrm{c}_{\mathrm{ij}} \mathrm{x}_{\mathrm{ij}}
$$

subject to

$$
\begin{gathered}
\sum_{j=1}^{m} x_{i j}-\sum_{k=1}^{m} x_{k i}=0 i=1,2 \ldots m \\
l_{i j} \leq x_{i j} \leq u_{i j} i, j=1,2 \ldots m
\end{gathered}
$$

where, $i$ and $j$ are the indices of node, $m=$ total number of nodes, $c_{i j}=$ costs per unit flow in arc from node $i$ to node $j, x_{i j}$ is amount of flow entering arc from node $i$ to node $j, j$ and $k=$ numbering of nodes, $\mathrm{l}_{\mathrm{ij}}=$ lower bound on flow in arc from node $\mathrm{i}$ to node $\mathrm{j}, \mathrm{u}_{\mathrm{ij}}=$ upper bound on flow in arc from node $\mathrm{i}$ to node j.

(2) Overview of Generalized Water Allocation Simulation Model

The GWASIM model [41,42] structured a water resources system in the network and solved the water allocation with an NFP algorithm [43]. GWASIM was a modified version of the MODSIM [44], a generalized river basin network flow simulation model at the Colorado State University, which uses the out-of-kilter algorithm $[45,46]$ to solve the NFP problem. The water resources system is represented 
in GWASIM as a network where each node is associated with one or several arcs. Seven different categories of nodes can be specified in the network. The different categories of nodes are inflow, confluence, diversion, reservoir, demand, flow-through demand and terminal (Figure 2). This model attaches artificial demand and storage arcs to demand and reservoir nodes automatically for computing the cost of water allocation. It can further split the artificial demand and storage arcs into several artificial sub-demands and sub-storages, which provides flexibility for users to allocate expected water for demand or storage. The mechanism of allocating water to demand or storage arcs following the operation rules is represented by priorities. In the GWASIM model, the priorities are converted into the cost coefficients of the artificial demand and storage arcs by the equation:

$$
c_{j}=-1000+10 \times \text { prior }_{j}
$$

where, $c_{j}=$ unit shipping cost of artificial $\operatorname{arc} j$, prior $_{j}=$ the priority of artificial arc $j$.

The minimum total cost of flow distribution in the network was optimized using the network flow programming algorithm. When utilizing GWASIM, the cost was presented as a priority and only the artificial terminal arcs were set with a positive cost of 0 . Artificial storage and demand arcs were set with negative cost coefficients so the water allocation principles of the system could be distinctly controlled (Table 2). The realistic diverting arcs can also be set with positive or negative costs to assign the direction of local inflow. The priority of artificial arcs can be confused if, according to Equation (7), the cost of realistic arcs is set over 10. Therefore, to avoid the augmentation of flow costs, more attention must be paid when setting the cost of realistic arcs.

Table 2. Allocation priorities of fractional demands and reservoir storage zones.

\begin{tabular}{|c|c|c|c|c|c|c|c|c|c|}
\hline \multirow[b]{2}{*}{ Demand Site } & \multicolumn{2}{|c|}{ Reservoir Storage } & \multicolumn{5}{|c|}{ Accumulated Demand Proportion } & \multicolumn{2}{|c|}{ Hydropower } \\
\hline & $S t^{1}$ & $P^{5}$ & $D \& I^{2}$ & $\mathrm{P}^{6}$ & $\mathrm{AG}^{3}$ & $\mathrm{P}^{6}$ & $P^{6} .\left(E^{4}.\right)$ & Hour & $\mathrm{P}^{6} \cdot\left(\mathrm{HP}^{5}\right)$ \\
\hline \multirow[t]{6}{*}{ Upstream } & & & $100 \%$ & 240 & $100 \%$ & 260 & & & \\
\hline & & & $90 \%$ & 170 & $90 \%$ & 190 & & & \\
\hline & & & $80 \%$ & 70 & $70 \%$ & 120 & & & \\
\hline & & & $60 \%$ & 60 & $60 \%$ & 110 & & & \\
\hline & & & $40 \%$ & 50 & $40 \%$ & 100 & & & \\
\hline & & & $20 \%$ & 40 & $20 \%$ & 90 & & & \\
\hline \multirow[t]{9}{*}{ Thac Mo } & FC & 300 & $100 \%$ & 240 & $100 \%$ & 260 & 280 & & \\
\hline & UP & 270 & & & & & & $\mathrm{~T}_{\mathrm{HH}}{ }^{9}$ & 250 \\
\hline & UL & 200 & $90 \%$ & 170 & $90 \%$ & 190 & & $\mathrm{~T}_{\mathrm{DH}}{ }^{8}$ & 180 \\
\hline & LL & 130 & $80 \%$ & 70 & $70 \%$ & 120 & & & \\
\hline & & & $60 \%$ & 60 & $60 \%$ & 110 & & & \\
\hline & & & $40 \%$ & 50 & $40 \%$ & 100 & & & \\
\hline & & & $20 \%$ & 40 & $20 \%$ & 90 & & & \\
\hline & $\mathrm{LP}$ & 30 & & & & & & $\mathrm{~T}_{\mathrm{LH}}{ }^{7}$ & 20 \\
\hline & Dead & 10 & & & & & & & \\
\hline \multirow[t]{7}{*}{ Can Don } & FC & 310 & $100 \%$ & 240 & $100 \%$ & 260 & & & \\
\hline & UL & 210 & $90 \%$ & 170 & $90 \%$ & 190 & & $\mathrm{~T}_{\mathrm{DH}}{ }^{8}$ & 180 \\
\hline & LL & 140 & $80 \%$ & 70 & $70 \%$ & 120 & & & \\
\hline & & & $60 \%$ & 60 & $60 \%$ & 110 & & & \\
\hline & & & $40 \%$ & 50 & $40 \%$ & 100 & & & \\
\hline & & & $20 \%$ & 40 & $20 \%$ & 90 & 280 & & \\
\hline & Dead & 10 & & & & & & & \\
\hline
\end{tabular}


Table 2. Cont.

\begin{tabular}{|c|c|c|c|c|c|c|c|c|c|}
\hline \multirow{2}{*}{ Demand Site } & \multicolumn{2}{|c|}{ Reservoir Storage } & \multicolumn{5}{|c|}{ Accumulated Demand Proportion } & \multicolumn{2}{|c|}{ Hydropower } \\
\hline & $\mathrm{St}^{1}$ & $\mathbf{P}^{5}$ & $D \& I^{2}$ & $\mathbf{P}^{6}$ & $\mathrm{AG}^{3}$ & $\mathrm{P}^{6}$ & $P^{6} .\left(E^{4}.\right)$ & Hour & $\mathrm{P}^{6} .\left(\mathrm{HP}^{5}\right)$ \\
\hline \multirow[t]{7}{*}{ SRPM } & FC & 320 & $100 \%$ & 240 & $100 \%$ & 260 & & & \\
\hline & UL & 220 & $90 \%$ & 170 & $90 \%$ & 190 & & $\mathrm{~T}_{\mathrm{DH}}^{8}$ & 180 \\
\hline & LL & 150 & $80 \%$ & 70 & $70 \%$ & 120 & & & \\
\hline & & & $60 \%$ & 60 & $60 \%$ & 110 & & & \\
\hline & & & $40 \%$ & 50 & $40 \%$ & 100 & & & \\
\hline & & & $20 \%$ & 40 & $20 \%$ & 90 & 280 & & \\
\hline & Dead & 10 & & & & & & & \\
\hline \multirow[t]{7}{*}{ Phuoc Hoa } & FC & 330 & & & $100 \%$ & 260 & & & \\
\hline & UL & 230 & & & $90 \%$ & 190 & & & \\
\hline & LL & 160 & & & $70 \%$ & 120 & & & \\
\hline & & & & & $60 \%$ & 110 & & & \\
\hline & & & & & $40 \%$ & 100 & & & \\
\hline & & & & & $20 \%$ & 90 & 280 & & \\
\hline & Dead & 10 & & & & & & & \\
\hline \multirow[t]{6}{*}{ Downstream } & & & $100 \%$ & 240 & $100 \%$ & 260 & & & \\
\hline & & & $90 \%$ & 170 & $90 \%$ & 190 & & & \\
\hline & & & $80 \%$ & 70 & $70 \%$ & 120 & & & \\
\hline & & & $60 \%$ & 60 & $60 \%$ & 110 & & & \\
\hline & & & $40 \%$ & 50 & $40 \%$ & 100 & & & \\
\hline & & & $20 \%$ & 40 & $20 \%$ & 90 & 280 & & \\
\hline Water diversion & & 290 & & & & & & & \\
\hline
\end{tabular}

(3) GWASIM formulation of Reservoir Operation Rule Curves and priority requirement for cascade reservoirs system

In the GWASIM, reservoir operation based on rule curves is simulated by setting ordered cost coefficients to artificial demand and storage arcs to reflect operating policy. The rule curves consist of upper and lower limits to guide the release to different water supply target amounts. For reservoirs with hydropower generation plants, the rule curves are those which will guide the generating hours for hydropower generation. The operating rule curves of the cascade reservoirs are shown in Figure 5. In this study, domestic and industrial demand were considered as the first priority. The priority for hydropower demand ranks behind domestic and industrial water demand, and ahead of agriculture and the flood storage zone of the reservoir. It should be noted here that the hydropower generation water requirement is the non-consumptive. The non-consumptive hydropower demand modeled using the flow-through demand method in GWASIM. The flow-through demand method iteratively removes the flow as a consumptive demand from the network and then adds the equal return flow at one specified return node (usually the next downstream). Therefore, water release for hydropower generation can be used for other purposes, such as domestic and industrial (D\&I), agriculture, water diversion, and environmental flow in the downstream area. The rations which followed the current rule curves of the cascade reservoirs and those rations are described below. When the water level in the reservoir is below the lower limit, only $80 \%$ of the total D\&I water demand and $70 \%$ of the agricultural demand will be satisfied first. When the water level in the reservoir lies between lower and upper limits, the water supply to D\&I demand and agriculture demand will be restricted to $90 \%$. When the water level in the reservoir is above the upper limit, each consumptive demand in this system should be fulfilled. For hydropower generation, the rule curves will guide the generating hours. In Thac Mo reservoir, the rule curves include both upper, lower hydropower limits which guide the generating hours for hydropower generation. When the water level is below the lower hydropower limit, the hydropower plant should operate with low-hours. When the water level in the reservoir is higher than the upper hydropower limit, the hydropower plant should operate with high-hours. When the water level in 
the reservoir lies between lower and upper hydropower limits, the hydropower plant should operate with demand-hours. In Can Don and SRPM reservoirs, the rule curves include both upper and lower limits which guide the generating hours for hydropower generation. When the water level is below the lower limit, the hydropower plant should operate with low-hours. When the water level in the reservoir is higher than the upper limit, the hydropower plant should operate with high-hours. When the water level in the reservoir lies between lower and upper limits, the hydropower plant should operate with demand-hours.

\subsubsection{The Optimization Algorithm}

BOBYQA [47] is a simple-bound-constrained nonlinear optimization algorithm. It uses a quadratic function to approximate the original objective function of the optimization problem, based on the evaluated objective function values on a set of initial guess points. Since the theoretical gradient of the approximated quadratic function can be efficiently derived, the algorithm avoids the need to calculate derivatives of objective function required by the conventional gradient-based approach $[47,48]$. This feature allows the algorithm to be more conveniently integrated with simulation models from different engineering problems [49-52], in which derivatives on decision variables might be hard and expensive to evaluate [53]. In this study, the BOBYQA algorithm was employed for solving a nonlinear optimization problem below:

$$
\operatorname{Min} F(x), x \in R^{n} \text { subject to bounds } a \leq x \leq b
$$

where $\mathrm{F}(\mathrm{x})$ is the objective function, $\mathrm{x}$ is the decision variables, $\mathrm{a}$ is lower bound and $\mathrm{b}$ is upper bound.

The BOBYQA algorithm applies a quadratic function to approximate the objective function on a set of interpolated points to produce more accurate solutions. The interpolation points are iteratively updated by the trust region approach until a local optimal solution is reached. The initial solution is required by multiple random generating and the updating produce will be lowered sharply until the best solution is achieved. More detail of the computational procedure of BOBYQA is provided by Chou and $\mathrm{Wu}[54]$.

\section{(1) General mathematical formulation}

A major difficulty in reservoir system operations is managing the inevitable conflict between competing objectives. Therefore, it is essential to determine balanced solutions between the conflicting objectives. In order to achieve the best solution to satisfy the objectives of this complex reservoir system, an optimization method was applied. Generally, optimization problems can be classified as either single-objective or multi-objective. The cascading reservoir system in the Be River basin is multi-purpose, so the optimization problem for this system was constructed as a multi-object problem. One of the techniques used to solve multi-objective optimization problems is aggregation approaches. Aggregation approaches are often used when assigning an objective function value to evaluate the dominance of solution sets, hence transforming the multi-objective optimization problem into a single-objective optimization. Two common methods within the aggregation approaches are the constraint method and the weighting method. The constraint method prioritizes one objective as the dominant objective and treats the other objectives as constraints. In this study, the constraint method was applied to find the optimal solutions to the multi-purpose multi-reservoir problem in the Be River basin. In the cascade reservoirs system, hydropower generation is maximized under the constraints of D\&I and agriculture water shortage. The constraints of the water shortage to agriculture were set to $30 \%$ and the D\&I water shortages were set to maximum annual DPD. 


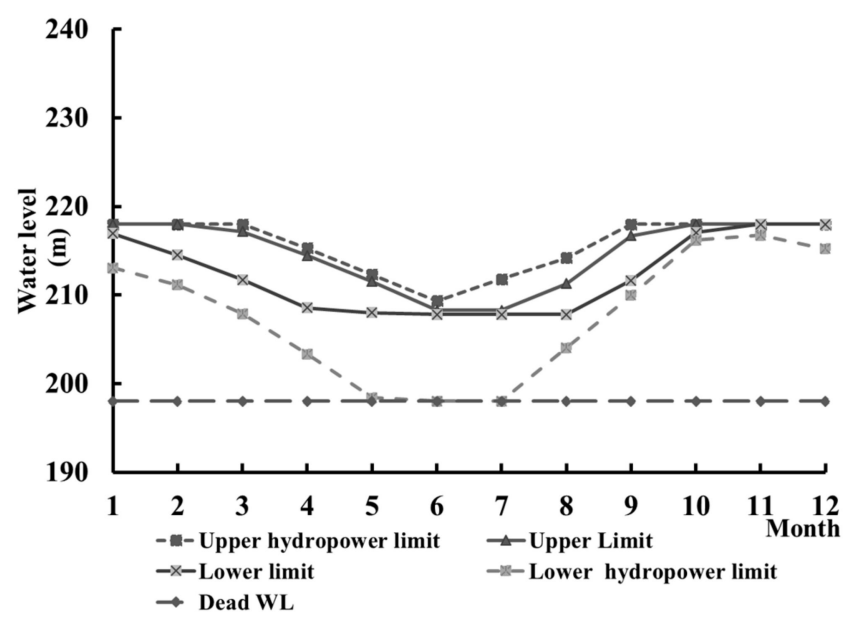

(a) Thac Mo

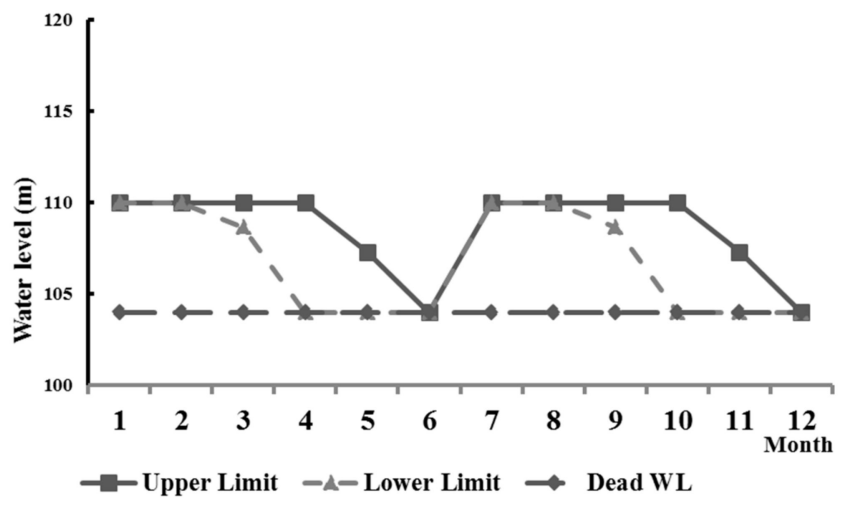

(b) Can Don

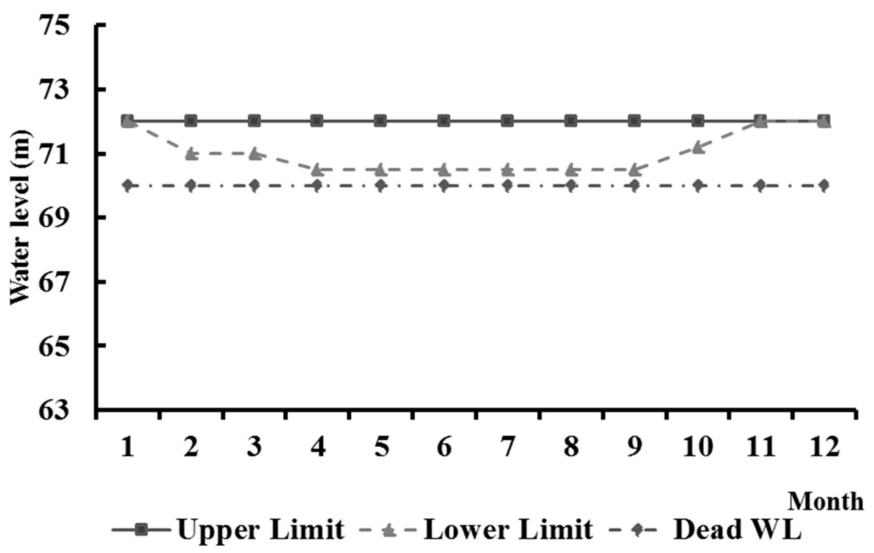

(c) SRPM

Figure 5. Cont. 


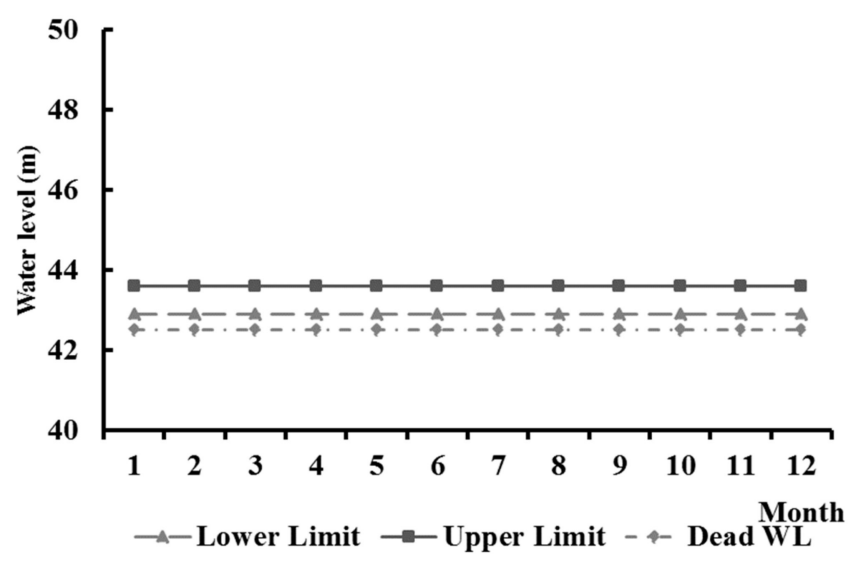

(d) Phuoc Hoa

Figure 5. Operation rule curves of cascade reservoirs.

\section{Objective function}

The objective of this study was to maximize hydropower generation from the three hydropower plants, while satisfying water shortage constraints.

$$
\mathrm{E}_{\mathrm{t}}=\operatorname{Max} \sum_{\mathrm{t}=1}^{\mathrm{T}} \sum_{\mathrm{r}=1}^{\mathrm{R}} \mathrm{E}_{\mathrm{r}, \mathrm{t}}
$$

where, $E_{r, t}$ is the total average annual energy of the reservoir; $t=1,2,3 \ldots . T ; T$ is the number of time steps in a simulation period; $r$ is the total number of reservoirs with hydro-generation, here $r=3$.

\section{Parameters}

The required water release from the reservoir for specific hydro generating electricity amounts is a nonlinear function of reservoir storage, the hydropower conversion efficiency, and the number of generating hours. The results of a previous study on the Be River basin also showed that the alternative of the number of generating hours is a sensitive effect to both terms of water supply and hydropower [55].

Therefore, hydropower reservoir operators pay more attention to finding a suitable number of generating hours. In this study, the number of generating hours in a day was the variable to seeking the optimal hydropower generation while satisfying water shortage constraints. The number of generating hours in a day is the same for all days in a month. Hydropower generation was optimized according to the generation hours using a simulation-optimization model in the present study. There were 12 variables corresponding to the number of generating hours in a day of 12 months for Thac Mo $\left(\mathrm{h}_{1,1}, \mathrm{~h}_{1.2}\right.$ $\left.\ldots \ldots \mathrm{h}_{1,11}, \mathrm{~h}_{1.12}\right)$, Can Don $\left(\mathrm{h}_{2,1}, \mathrm{~h}_{2,2} \ldots \ldots \mathrm{h}_{2.11}, \mathrm{~h}_{2,12}\right)$, SRPM $\left(\mathrm{h}_{3,1}, \mathrm{~h}_{3,2} \ldots \ldots \mathrm{h}_{3,11}, \mathrm{~h}_{3,12}\right)$ reservoirs. Therefore, the total number of parameters to be optimized was 36 . Two inequality constraints were defined as follows:

The maximum required water shortage for agriculture and D\&I demand

$$
\begin{gathered}
\operatorname{Max}_{\mathrm{SR}} \leq 30 \% \\
\text { Max DPD } \leq \text { DPD constraint }
\end{gathered}
$$

where $\mathrm{SR}_{\mathrm{AG}}$ is the annual shortage rate of agricultural water supply, DPD is deficit percent day index of D\&I water supply.

In this study, a water shortage of $30 \%$ was considered generally acceptable for agricultural water supply. According to the reliability of water supply, if water shortage is more than $30 \%$, the operational status of a water resource system can be described as unsatisfactory. In these cases, it is necessary to improve the effectiveness of the agriculture system and adjust cropping systems to better handle 
water shortages. For D\&I water supply, the acceptable DPD is around 600\%-day to 1500\%-day with the SR between 5\% and 10\%, across a five-month period. The dry season in the Be River basin lasts five months from December to April for a maximum of 150 days. Therefore, the number of days of water shortage should be set to below 150 days in this study. If an SR between 5\% and 10\% occurs over 150 days, the water supply system can generally be maintained at a near-tolerance level without causing significant socioeconomic impact with a minor effort of water conservation or water reallocation. The maximum annual shortage value of DPD, an extreme index of water shortage, was used to reflect the severity of the most extreme drought event in history, which has generated growing concern of apparent vulnerability in this area $[4,5]$.

To accommodate these constraints, the formulation of optimizing can be presented as below:

$$
\mathrm{E}_{\mathrm{t}}=\operatorname{Max} \sum_{\mathrm{t}=1}^{\mathrm{T}} \sum_{\mathrm{r}=1}^{\mathrm{R}} \mathrm{E}_{\mathrm{r}, \mathrm{t}}-\mathrm{w}_{\mathrm{r}, \mathrm{t}} \mathrm{P}_{\mathrm{r}, \mathrm{t}}
$$

where, $P_{r, t}$ is penalty functions punish water shortage situations; $w_{r, t}$ is the weighting factor.

The penalty function used in agricultural water shortage is defined by the equation below:

$$
\mathrm{P}_{\mathrm{r}, \mathrm{t}}=\left(\mathrm{SR}_{\mathrm{r}, \mathrm{t}}-0.3\right)^{2} \text { if } \mathrm{SR}_{\mathrm{r}, \mathrm{t}} \geq 0.3 ; 0 \text { otherwise }
$$

The penalty function used in D\&I water shortage is defined by the equation below:

$$
\mathrm{P}_{\mathrm{r}, \mathrm{t}}=\left(\mathrm{DPD}_{\mathrm{r}, \mathrm{t}}-\mathrm{DPD}_{\text {constraint }}\right)^{2} \text { if } \mathrm{DPD}_{\mathrm{r}, \mathrm{t}} \geq \mathrm{DPD}_{\text {constraint }} ; 0 \text { otherwise }
$$

where, $\mathrm{P}_{\mathrm{r}, \mathrm{t}}$ is a penalty applied to the violation of water shortage in period $\mathrm{t}$.

\section{Results and Discussion}

This study focused on optimizing hydropower generation with water shortage constraints. The maximum values DPD, an extreme-index of shortage, and SR, a first-order index, were used and considered as constraints when optimizing hydropower generation. Seven water shortage scenarios with varying D\&I water shortage conditions were defined using seven DPD constraints. The seven scenarios were defined with a maximum annual DPD value of $600 \%$ per day, $750 \%$ per day, $900 \%$ per day, $1050 \%$ per day, $1200 \%$ per day, $1350 \%$ per day and $1500 \%$ per day, representing the tolerance of a 10\% maximum shortage rate lasting 60 days, 75 days, 90 days, 105 days, 120 days, 135 days, and 150 days. The daily generating hours of three cascade reservoir hydropower plants in the Be River basin were taken as the decision variables, and the results are presented in Table 3. Hydropower generation policies in seven scenarios were optimized then compared against the present operating policy using three water shortage indices-SR, SI, and DPD. A trade-off curve was constructed to represent the relationship between the hydropower generation and water supply of the system.

\subsection{Annual Power Production}

The significant enhancements of energy and the decrease in water shortage were observed and compared to the present scenario, as shown in Table 4 . The objective function of hydropower generation for Scenario 1 improved from the existing energy value of $1223 \times 10^{6} \mathrm{kWh}$ to $1266 \times 10^{6} \mathrm{kWh}$ and the water supply improved significantly, with the value of DPD decreasing to 611 from the existing value of 3873. Similarly, the objective function of hydropower generation for Scenarios 2, 3, and 4 increased to $1275 \times 10^{6} \mathrm{kWh}, 1284 \times 10^{6} \mathrm{kWh}$, and $1292 \times 10^{6} \mathrm{kWh}$ respectively. Improvements in the hydropower generation were achieved in Scenarios 5, 6, 7. Hydropower generation increased from the existing energy value of $1223 \times 10^{6} \mathrm{kWh}$ to $1292 \times 10^{6} \mathrm{kWh}, 1293 \times 10^{6} \mathrm{kWh}$, and $1293 \times 10^{6} \mathrm{kWh}$ respectively. Meanwhile, there were significant reductions in the maximum DPD, from 3873 to 1294 , 1382 and 1575 respectively. The highest improvement in energy, obtained by the optimized energy policy, was about $5.74 \%$ better than those obtained by the present operating policy, while the DPD 
value decreased from 3873 to 1575 . Reducing the DPD value from 3873 to 1575 means the maximum SR of D\&I water supply reduces from $26 \%$ to $10 \%$ for the last six months of the dry season.

Table 3. Optimized generating hour of different water shortage scenarios.

\begin{tabular}{|c|c|c|c|c|c|c|c|c|c|c|c|c|c|c|}
\hline \multirow{2}{*}{$\mathrm{Sc}^{1}$} & \multirow{2}{*}{ Reservoir } & \multicolumn{12}{|c|}{ Month } & \multirow[t]{2}{*}{$\mathrm{Ave}^{2}$} \\
\hline & & 1 & 2 & 3 & 4 & 5 & 6 & 7 & 8 & 9 & 10 & 11 & 12 & \\
\hline \multirow{3}{*}{1} & Thac Mo & 5.9 & 15.3 & 7.9 & 6.0 & 7.0 & 6.0 & 6.5 & 6.6 & 4.3 & 4.5 & 7.2 & 6.9 & 7.0 \\
\hline & Can Don & 3.0 & 2.1 & 2.8 & 3.3 & 4.9 & 3.6 & 3.4 & 4.6 & 3.9 & 3.9 & 4.1 & 2.5 & 3.5 \\
\hline & SRPM & 3.0 & 2.1 & 2.1 & 2.5 & 3.0 & 3.1 & 4.1 & 4.0 & 4.7 & 3.6 & 3.4 & 2.5 & 3.2 \\
\hline & Thac Mo & 10.1 & 10.1 & 10.3 & 6.6 & 12.1 & 12.0 & 12.0 & 12.5 & 6.8 & 12.3 & 12.0 & 10.1 & 10.6 \\
\hline \multirow[t]{3}{*}{2} & Can Don & 3.4 & 4.6 & 3.0 & 3.3 & 3.6 & 3.6 & 4.6 & 4.0 & 4.0 & 3.9 & 3.9 & 4.5 & 3.9 \\
\hline & SRPM & 3.3 & 2.0 & 4.2 & 2.0 & 3.3 & 4.1 & 3.7 & 4.4 & 3.6 & 3.9 & 3.4 & 3.9 & 3.5 \\
\hline & Thac Mo & 11.4 & 11.3 & 24.0 & 6.5 & 12.0 & 14.7 & 13.1 & 14.2 & 13.1 & 13.8 & 12.2 & 11.0 & 13.1 \\
\hline \multirow[t]{3}{*}{3} & Can Don & 3.5 & 5.2 & 2.5 & 4.2 & 4.4 & 4.0 & 4.7 & 4.6 & 4.1 & 2.7 & 4.6 & 4.1 & 4.0 \\
\hline & SRPM & 3.2 & 3.4 & 2.2 & 2.0 & 2.1 & 5.6 & 3.7 & 4.5 & 4.4 & 3.2 & 4.0 & 2.2 & 3.4 \\
\hline & Thac Mo & 17.1 & 17.0 & 16.9 & 5.5 & 19.0 & 19.0 & 19.0 & 18.8 & 18.3 & 19.0 & 19.1 & 17.0 & 17.1 \\
\hline \multirow[t]{3}{*}{4} & Can Don & 3.3 & 4.5 & 3.0 & 3.3 & 4.2 & 3.7 & 4.6 & 4.0 & 4.0 & 3.9 & 4.0 & 4.4 & 3.9 \\
\hline & SRPM & 3.3 & 3.8 & 2.1 & 2.0 & 3.0 & 4.0 & 3.8 & 4.4 & 3.6 & 3.8 & 3.5 & 4.0 & 3.4 \\
\hline & Thac Mo & 21.9 & 22.2 & 19.1 & 16.8 & 21.7 & 23.8 & 23.9 & 18.9 & 18.0 & 21.4 & 19.8 & 19.0 & 20.5 \\
\hline \multirow[t]{3}{*}{5} & Can Don & 3.9 & 4.3 & 3.9 & 3.5 & 2.1 & 3.5 & 4.0 & 3.9 & 4.0 & 4.0 & 4.0 & 4.0 & 3.8 \\
\hline & SRPM & 3.2 & 4.0 & 4.4 & 2.0 & 2.1 & 3.8 & 3.9 & 4.1 & 3.8 & 4.0 & 3.9 & 4.1 & 3.6 \\
\hline & Thac Mo & 21.2 & 22.7 & 18.2 & 4.8 & 20.7 & 23.0 & 23.0 & 18.0 & 17.5 & 20.4 & 18.8 & 18.1 & 18.9 \\
\hline \multirow[t]{3}{*}{6} & Can Don & 3.5 & 4.9 & 3.2 & 3.6 & 4.0 & 3.8 & 4.8 & 4.2 & 4.2 & 4.2 & 4.2 & 4.7 & 4.1 \\
\hline & SRPM & 3.6 & 4.0 & 3.1 & 2.3 & 3.4 & 4.3 & 4.1 & 4.6 & 3.9 & 4.1 & 3.8 & 4.3 & 3.8 \\
\hline & Thac Mo & 23.1 & 24.0 & 24.0 & 5.3 & 19.6 & 23.1 & 23.0 & 18.0 & 17.4 & 20.4 & 22.9 & 23.0 & 20.3 \\
\hline \multirow[t]{2}{*}{7} & Can Don & 3.3 & 4.6 & 3.0 & 3.3 & 3.6 & 3.4 & 5.0 & 5.0 & 4.0 & 4.0 & 4.9 & 5.0 & 4.1 \\
\hline & SRPM & 3.3 & 3.8 & 3.0 & 3.5 & 3.1 & 4.1 & 3.7 & 4.4 & 3.6 & 3.8 & 3.5 & 3.9 & 3.7 \\
\hline
\end{tabular}

Table 4. Optimized annual hydropower production and maximum annual deficit percent day (DPD) of different water shortage scenarios.

\begin{tabular}{ccccccc}
\hline \multirow{2}{*}{ Scenario } & $\begin{array}{c}\text { DPD } \\
\text { Constraint }\end{array}$ & \multicolumn{2}{c}{ Simulated Result } & \multicolumn{2}{c}{ Optimized Results } & Energy \\
\cline { 3 - 6 } & $\begin{array}{c}\text { Energy } \\
\mathbf{1 0}^{\mathbf{6}} \mathbf{k W h}\end{array}$ & DPD & $\begin{array}{c}\text { Energy } \\
\mathbf{1 0}^{\mathbf{6}} \mathbf{k W h}\end{array}$ & DPD & $\begin{array}{c}\text { Improvement } \\
\%\end{array}$ \\
\hline 1 & 600 & & 1266 & 617 & $3.51 \%$ \\
2 & 750 & & 1275 & 804 & $4.25 \%$ \\
3 & 900 & & & 1284 & 911 & $5.00 \%$ \\
4 & 1050 & 1223 & 3873 & 1292 & 1058 & $5.64 \%$ \\
5 & 1200 & & & 1292 & 1294 & $5.67 \%$ \\
6 & 1350 & & & 1293 & 1382 & $5.72 \%$ \\
7 & 1500 & & & 1293 & 1575 & $5.74 \%$ \\
\hline
\end{tabular}

Furthermore, the results indicate that optimal operation policy offers advantages in water supply in considering both the SI and SR values, as shown in Table 5. The maximum SI value of D\&I water supply is around 1, the designed shortage index for water supply in Taiwan [56], and the average SR is $10 \%$, an acceptable value of water shortage for agriculture. The maximum SI of D\&I and agricultural water supply were 0.067 and 1.031 respectively in Scenario 7. It can be seen that the SR of agriculture followed a similar trend to that of the SI, with its value below $10 \%$, as shown in Table 5. Although the maximum SI value was around 1, DPD could still get as high a value as 1575 in Scenario 7. This shows that the DPD is able to explore the severity of the deficit event, implying a stricter criterion to explore the severity of drought events. Overall, the optimal hydropower generation policies for cascade reservoirs in this study would be significantly better than the present operation practice for both meeting the total water supply and hydropower generation. 
Table 5. Water shortage indices of different water shortage scenarios.

\begin{tabular}{cccccc}
\hline \multirow{2}{*}{$\begin{array}{c}\text { Scenario } \\
\text { No. }\end{array}$} & DPD & Shortage Index (SI) & \multicolumn{2}{c}{ Shortage Rate (SR) } \\
\cline { 3 - 6 } & & D\&I & AG & $\begin{array}{c}\text { Max. Annual } \\
\text { Shortage Rate }\end{array}$ & $\begin{array}{c}\text { Average } \\
\text { Shortage Rate }\end{array}$ \\
\hline 1 & 617 & 0.003 & 0.162 & $10 \%$ & $0 \%$ \\
2 & 804 & 0.007 & 0.308 & $10 \%$ & $5 \%$ \\
3 & 911 & 0.011 & 0.369 & $13 \%$ & $6 \%$ \\
4 & 1058 & 0.019 & 0.701 & $13 \%$ & $6 \%$ \\
5 & 1294 & 0.043 & 0.956 & $13 \%$ & $10 \%$ \\
6 & 1382 & 0.038 & 0.957 & $13 \%$ & $10 \%$ \\
7 & 1575 & 0.067 & 1.031 & $14 \%$ & $10 \%$ \\
\hline
\end{tabular}

\subsection{The Trade-off between Hydropower Generation and Water Supply}

The relationship between water supply and hydropower generation for various scenarios is listed in Table 4 and plotted in Figure 6. The trade-off between hydropower generation and water supply for consumptive uses is shown in Figure 6. It can be seen that power production increases when the DPD value increases. This means that power production increases with a decrease in the water supply release. This is due to the fact that when the quantity of inflow decreases, the DPD value will increase, and the reliability of water supply will decrease. This shows that the power production and the water supply release have conflicting objectives in this case. Based on Table 4 , an increase from $3.51 \%$ to $5.74 \%$ in hydropower generation results in an increase of DPD from 617 to 1575. In Scenario 1, the value of the DPD constraint was 600, producing a maximum of $1265.96 \times 10^{6} \mathrm{kWh}$ of hydropower with $3.51 \%$ energy improvement compared to the present operating policy. The water shortage was much less with the DPD value of 617 to achieve a reliable water supply. The model tends to satisfy the constraints by releasing more for water supply. In Scenario 2, the maximum annual hydropower production was $1275.04 \times 10^{6} \mathrm{kWh}$, which is also a $4.25 \%$ increase from the existing energy value. The water supply releases were also reduced due to an increase in DPD constraints. In Scenario 3, the DPD value was 911 , and the maximum annual power production increased to $1284.10 \times 10^{6} \mathrm{kWh}$. The average power generation increased by $5.64 \%, 5.67 \%, 5.72 \%$ and $5.74 \%$ of the existing energy value in Scenarios 4, 5, 6, and 7 respectively. The hydropower production varied from $1291.93 \times 10^{6} \mathrm{kWh}$ for Scenario 4 and to $1293.25 \times 10^{6} \mathrm{kWh}$ for Scenario 7. This translates to a water deficit with DPD values from 1058 to 1575 . In Scenarios 5, 6, and 7 the variation in power production among the different DPD conditions was less than for the other scenarios. The variation in power production between Scenarios 5 and 7 was $0.1 \%$. This shows that when the inflow is very low, the constraints on releases have a slight effect on power production. To achieve high generating hours, the reservoir will release water to satisfy the hydropower generation requirements instead of maintaining huge stores for the next operation period. This is because there is less storage and lower net head available during these periods. This may lead to less water being released to accomplish the hydropower generation task for the next term. In general, these seven scenarios can represent the conflicts in water sharing between water supply and energy. 


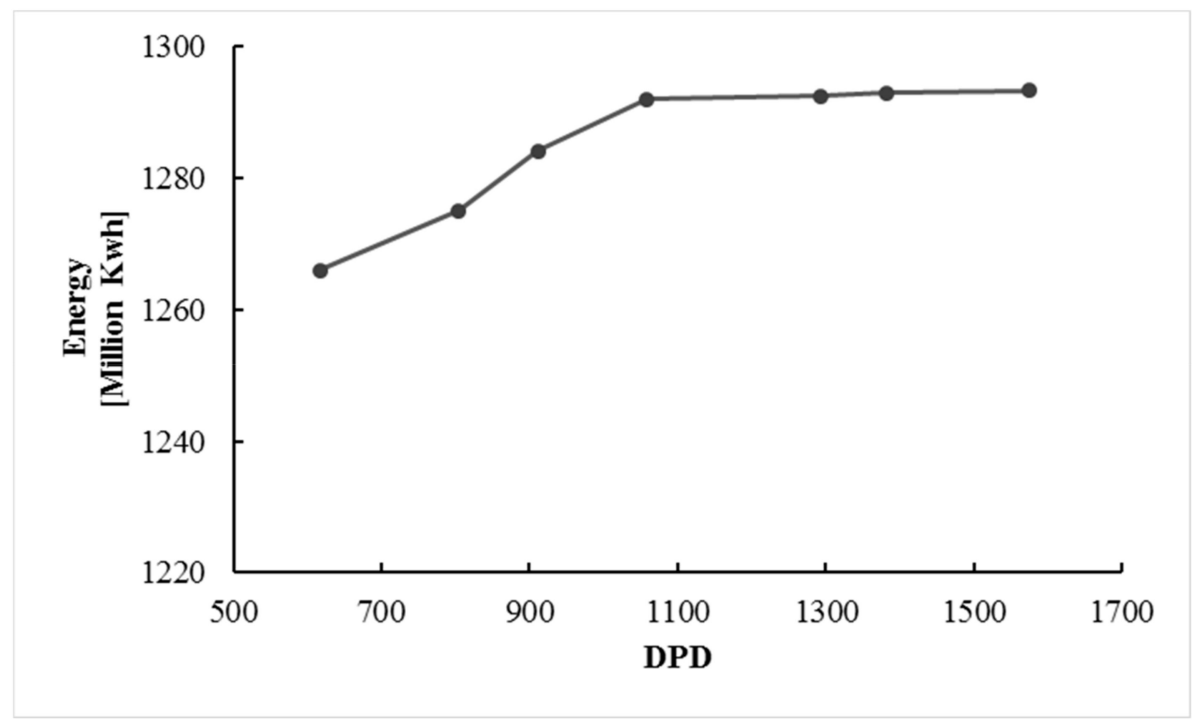

Figure 6. Trade-off between maximum annual hydropower production and DPD of various water shortage scenarios.

\section{Conclusions}

This study applied a simulation-optimization model to maximize hydropower generation within the constraints of water shortage scenarios. The shortage indices, SR, SI, and DPD, are adopted to describe the characteristics of water shortages for agriculture and D\&I water supply more precisely. Optimized hydropower generation policies would significantly and simultaneously improve the present operating policy in achieving the two competing objectives of total water supply and hydropower generation. The solution obtained by the optimized energy policy is approximately $5.74 \%$ higher than those obtained by the present operating policy, while simultaneously reducing the DPD value from 3873 to 1575 . The trade-off curve was constructed to represent a relationship between hydropower generation and water supply that will provide flexibility to the reservoir operator when managing water shortages. This study proposed a methodology to investigate complex interactions of the water-energy in a complex multi-purpose multi-reservoir system. Further studies could incorporate food security criteria to find more comprehensive policies that coordinate water, energy, and food. Overall, this study provides insight into the performance of multipurpose cascade reservoirs to aid decision making and builds a foundation for future research in meeting the challenges of global water and energy demands.

Author Contributions: Conceptualization, F.N.-F.C. and N.T.T.L.; methodology, F.N.-F.C. and C.-W.W.; software, N.T.T.L. and C.-W.W.; formal analysis, N.T.T.L.; investigation, F.N.-F.C.; resources, N.T.T.L. and F.N.-F.C.; data curation, N.T.T.L.; writing-original draft preparation, N.T.T.L. and F.N.-F.C.; writing-review and editing, C.-W.W.; visualization, N.T.T.L.; supervision, N.T.T.L.; project administration, F.N.F.C.; funding acquisition, N.T.T.L. and F.N.-F.C. All authors have read and agreed to the published version of the manuscript.

Funding: This research received no external funding.

Acknowledgments: Nguyen Thi Thuy Linh was supported by a PhD scholarship granted by MOST, Taiwan, under the PhD Programme, grant number: 2016009

Conflicts of Interest: The authors declare no conflicts of interest.

\section{References}

1. Nguyen, H.; Shaw, R. Drought Risk Management in Vietnam. Droughts in Asian Monsoon Region; Emerald Group Publishing Limited: Bingley, UK, 2011; Chapter 8, pp. 141-161.

2. Vu-Thanh, H.; Ngo-Duc, T.; Phan-Van, T. Evolution of meteorological drought characteristics in Vietnam during the 1961-2007 period. Theor. Appl. Climatol. 2014, 118, 367-375. [CrossRef] 
3. Vu, M.T.; Raghavan, S.V.; Pham, D.M.; Liong, S.Y. Investigating drought over the Central Highland, Vietnam, using regional climate models. J. Hydrol. 2015, 526, 265-273. [CrossRef]

4. Noi, L.V.; Nitivattananon, V. Assessment of vulnerabilities to climate change for urban water and wastewater infrastructure management: Case study in Dong Nai river basin, Vietnam. Environ. Dev. 2015, 16, 119-137. [CrossRef]

5. Truong, N.; Nguyen, H.; Kondoh, A. Land Use and Land Cover Changes and Their Effect on the Flow Regime in the Upstream Dong Nai River Basin, Vietnam. Water 2018, 10, 1206. [CrossRef]

6. Chandramouli, V.; Raman, H. Multi-reservoir modeling with dynamic programming and neural networks. J. Water Resour. Plan. Manag. 2001, 127, 89-98. [CrossRef]

7. Labadie, J.W. Optimal operation of multi-reservoir systems: State-of-the-art review. J. Water Resour. Plan. Manag. 2004, 130, 93-111. [CrossRef]

8. Reddy, M.J.; Kumar, D.N. Optimal reservoir operation using multi-objective evolutionary algorithm. Water Resour. Manag. 2006, 20, 861-878. [CrossRef]

9. Kumar, D.N.; Reddy, M.J. Ant colony optimization for multi-purpose reservoir operation. Water Resour. Manag. 2006, 20, 879-898. [CrossRef]

10. Nagesh Kumar, D.; Janga Reddy, M. Multipurpose reservoir operation using particle swarm optimization. J. Water Resour. Plan. Manag. 2007, 133, 192-201. [CrossRef]

11. Rani, D.; Moreira, M.M. Simulation-optimization modeling: A survey and potential application in reservoir systems operation. Water Resour. Manag. 2010, 24, 1107-1138. [CrossRef]

12. Khosrojerdi, T.; Moosavirad, S.H.; Ariafar, S.; Ghaeini-Hessaroeyeh, M. Optimal Allocation of Water Resources Using a Two-Stage Stochastic Programming Method with Interval and Fuzzy Parameters. Nat. Resour. Res. 2019, 28, 1107-1124. [CrossRef]

13. Cancelliere, A.; Giuliano, G.; Ancarani, A.; Rossi, G. A neural networks approach for deriving irrigation reservoir operating rules. Water Resour. Manag. 2002, 16, 71-88. [CrossRef]

14. Koutsoyiannis, D.; Economou, A. Evaluation of the parameterization-simulation-optimization approach for the control of reservoir systems. Water Resour. Res. 2003, 39. [CrossRef]

15. Wang, Y.; Yoshitani, J.; Fukami, K. Stochastic multi-objective optimization of reservoirs in parallel. Hydrol. Process. Int. J. 2005, 19, 3551-3567. [CrossRef]

16. Suiadee, W.; Tingsanchali, T. A combined simulation-genetic algorithm optimization model for optimal rule curves of a reservoir: A case study of the Nam Oon Irrigation Project, Thailand. Hydrol. Process. Int. J. 2007, 21, 3211-3225. [CrossRef]

17. Shourian, M.; Mousavi, S.; Tahershamsi, A. Basin-wide water resources planning by integrating PSO algorithm and MODSIM. Water Resour. Manag. 2008, 22, 1347-1366. [CrossRef]

18. Wurbs, R.A.; Karama, A.S. Salinity and water-supply reliability. J. Water Resour. Plan. Manag. 1995, 121, 352-358. [CrossRef]

19. Dhar, A.; Datta, B. Optimal operation of reservoirs for downstream water quality control using linked simulation optimization. Hydrol. Process. Int. J. 2008, 22, 842-853. [CrossRef]

20. Chen, L. Real coded genetic algorithm optimization of long term reservoir operation 1. J. Am. Water Resour. Assoc. 2003, 39, 1157-1165. [CrossRef]

21. Oliveira, R.; Loucks, D.P. Operating rules for multi-reservoir systems. Water Resour. Res. 1997, 33, 839-852. [CrossRef]

22. Hsu, S.-K. Shortage indices for water-resources planning in Taiwan. J. Water Resour. Plan. Manag. 1995, 121, 119-131. [CrossRef]

23. Srdjevic, B.; Medeiros, Y.; Faria, A. An objective multi-criteria evaluation of water management scenarios. Water Resour. Manag. 2004, 18, 35-54. [CrossRef]

24. Shiau, J.-T.; Lee, H. Derivation of optimal hedging rules for a water-supply reservoir through compromise programming. Water Resour. Manag. 2005, 19, 111-132. [CrossRef]

25. Kang, L.; Zhang, S.; Ding, Y.; He, X. Extraction and preference ordering of multi-reservoir water supply rules in dry years. Water 2016, 8, 28. [CrossRef]

26. Chang, Y.T.; Chang, L.C.; Chang, F.J. Intelligent control for modeling of real-time reservoir operation, part II: Artificial neural network with operating rule curves. Hydrol. Process. Int. J. 2005, 19, 1431-1444. [CrossRef]

27. Chang, F.-J.; Wang, Y.-C.; Tsai, W.-P. Modelling intelligent water resources allocation for multi-users. Water Resour. Manag. 2016, 30, 1395-1413. [CrossRef] 
28. Chang, F.J.; Lai, J.S.; Kao, L.S. Optimization of operation rule curves and flushing schedule in a reservoir. Hydrol. Process. 2003, 17, 1623-1640. [CrossRef]

29. Yang, C.-C.; Chang, L.-C.; Yeh, C.-H.; Chen, C.-S. Multi-objective planning of surface water resources by multi-objective genetic algorithm with constrained differential dynamic programming. J. Water Resour. Plan. Manag. 2007, 133, 499-508. [CrossRef]

30. Hsu, N.S.; Cheng, W.C.; Cheng, W.M.; Wei, C.C.; Yeh, W.W. Optimization and capacity expansion of a water distribution system. Adv. Water Resour. 2008, 31, 776-786. [CrossRef]

31. Chang, L.-C.; Chang, F.-J. Multi-objective evolutionary algorithm for operating parallel reservoir system. J. Hydrol. 2009, 377, 12-20. [CrossRef]

32. Yang, C.-C.; Chang, L.-C.; Chen, C.-S.; Yeh, M.-S. Multi-objective planning for conjunctive use of surface and subsurface water using genetic algorithm and dynamics programming. Water Resour. Manag. 2009, 23, 417-437. [CrossRef]

33. Hashimoto, T.; Loucks, D.P.; Stedinger, J.R. Reliability, resiliency, robustness, and vulnerability criteria for water resource systems. Water Resour. Res. 1982, 18.

34. Moy, W.S.; Cohon, J.L.; ReVelle, C.S. A programming model for analysis of the reliability, resilience, and vulnerability of a water supply reservoir. Water Resour. Res. 1986, 22, 489-498. [CrossRef]

35. Zongxue, X.; Jinno, K.; Kawamura, A.; Takesaki, S.; Ito, K. Performance risk analysis for Fukuoka water supply system. Water Resour. Manag. 1998, 12, 13-30. [CrossRef]

36. Maier, H.R.; Lence, B.J.; Tolson, B.A.; Foschi, R.O. First-order reliability method for estimating reliability, vulnerability, and resilience. Water Resour. Res. 2001, 37, 779-790. [CrossRef]

37. Fowler, H.; Kilsby, C.; O'Connell, P. Modeling the impacts of climatic change and variability on the reliability, resilience, and vulnerability of a water resource system. Water Resour. Res. 2003, 39. [CrossRef]

38. Kjeldsen, T.R.; Rosbjerg, D. Choice of reliability, resilience and vulnerability estimators for risk assessments of water resources systems/Choix d'estimateurs de fiabilité, de résilience et de vulnérabilité pour les analyses de risque de systèmes de ressources en eau. Hydrol. Sci. J. 2004, 49. [CrossRef]

39. Jain, S.; Bhunya, P. Reliability, resilience and vulnerability of a multipurpose storage reservoir/Confiance, résilience et vulnérabilité d'un barrage multi-objectifs. Hydrol. Sci. J. 2008, 53, 434-447. [CrossRef]

40. Asefa, T.; Clayton, J.; Adams, A.; Anderson, D. Performance evaluation of a water resources system under varying climatic conditions: Reliability, Resilience, Vulnerability and beyond. J. Hydrol. 2014, 508, 53-65. [CrossRef]

41. Chou, F.N.F.; Wu, C.W.; Lin, C.H. Simulating multi-reservoir operation rules by network flow model. Operating Reservoirs in Changing Conditions. In Proceedings of the Operations Management Conference, Sacramento, CA, USA, 14-16 August 2006; pp. 335-344.

42. Chou, F.N.-F.; Wu, C. Reducing the impacts of flood-induced reservoir turbidity on a regional water supply system. Adv. Water Resour. 2010, 33, 146-157. [CrossRef]

43. Yerram reddy, A.R.; Wurbs, R.A. Water resources allocation based on network flow programming. Civ. Eng. Syst. 1996, 13, 75-87. [CrossRef]

44. Labadie, J.W.; Bode, D.A.; Pineda, A.M. Network model for decision support in municipal raw water supply 1. J. Am. Water Resour. Assoc. 1986, 22, 927-940. [CrossRef]

45. Barr, R.S.; Glover, F.; Klingman, D. An improved version of the out-of-kilter method and a comparative study of computer codes. Math. Program. 1974, 7, 60-86. [CrossRef]

46. Fulkerson, D.R. An out-of-kilter method for minimal-cost flow problems. J. Soc. Ind. Appl. Math. 1961, 9, 18-27. [CrossRef]

47. Powell, M.J. The BOBYQA Algorithm for Bound Constrained Optimization without Derivatives; Cambridge NA Report NA2009/06; University of Cambridge: Cambridge, UK, 2009; pp. 26-46.

48. Martinez-Cantin, R. Bayesopt: A bayesian optimization library for nonlinear optimization, experimental design and bandits. J. Mach. Learn. Res. 2014, 15, 3735-3739.

49. Jin, C.; Zhao, W.; Normani, S.D.; Zhao, P.; Emelko, M.B. Synergies of media surface roughness and ionic strength on particle deposition during filtration. Water Res. 2017, 114, 286-295. [CrossRef]

50. Appel, S.; Reimann, S. Beam Line Optimization Using Derivative-Free Algorithms. In Proceedings of the 10th International Particle Accelerator Conference (IPAC'19), Melbourne, Australia, 19-24 May 2019. 
51. Foks, S.S.; Raffensperger, J.P.; Penn, C.A.; Driscoll, J.M. Estimation of Base Flow by Optimal Hydrograph Separation for the Conterminous United States and Implications for National-Extent Hydrologic Models. Water 2019, 11, 1629. [CrossRef]

52. Lüthi, M. Stream Gauge Calibration of a Cave Stream Using Water Temperature Variability as a Tracer. Water Resour. Res. 2019, 55, 5738-5750. [CrossRef]

53. Chen, M.; Izady, A.; Abdalla, O.A. An efficient surrogate-based simulation-optimization method for calibrating a regional MODFLOW model. J. Hydrol. 2017, 544, 591-603. [CrossRef]

54. Chou, F.N.-F.; Wu, C.-W. Stage-wise optimizing operating rules for flood control in a multi-purpose reservoir. J. Hydrol. 2015, 521, 245-260. [CrossRef]

55. Chou, F.N.; Nguyen, L.T. Comparing the Generating Strategies of Hydropower of Cascade Reservoirs to Mitigate the Shortage of Water Supply. In Proceedings of the 12th International Conference on Hydroscience \& Engineering, Tainan, Taiwan, 6-10 November 2016.

56. Huang, W.C.; Yuan, L.C.; Lee, C.M. Linking genetic algorithms with stochastic dynamic programming to the long-term operation of a multi-reservoir system. Water Resour. Res. 2002, 38. [CrossRef]

(C) 2020 by the authors. Licensee MDPI, Basel, Switzerland. This article is an open access article distributed under the terms and conditions of the Creative Commons Attribution (CC BY) license (http://creativecommons.org/licenses/by/4.0/). 